\title{
CONTRIBUIÇÃO PARA UMA POSTURA HUMANA EM SITUAÇĀO QUE SE RELACIONA COM A MORTE
}

\author{
Maria Antonia Paduan de Oliveira* \\ Mizue Ogasawara*
}

OLIVEIRA, M.A.P. de; OGASAWARA, M. Contribuiçăo para uma postura humana em situaçăo que se relaciona com a morte. Rev. Esc. Enf. USP., v. 26, n. 3, p. ～- , dez. 1992

O presente artigo foi produzido na tentativa de subsidiar os estudantes perante a situação da morte. Trata-se de conceitos e conflitos relacionados com a morte e fase terminal, atitudes que axigem envolvimento profissional nesta situação e outras informaçōes complementares.

UNITERMOS: Cuidados finais. Morte. Assistência de enfermagem.

\section{Apresentaçáo}

Este artigo surgiu da necessidade de esclarecimento identificada em alunos da disciplina de Enfermagem médico-cirúrgica 1, que iniciam a vivência de situações de morte e fase terminal no estágio hospitalar.

Pretende contribuir para o esclarecimento do conceito de morte e conseqüentes conflitos, bem como discorrer sobre as atitudes que exigem envolvimento profissional diante da situação de morte na fase iminente, terminal e pós-morte.

\section{A morte e o doente terminal}

Terminalidade significa a fase final da vida de uma pessoa na condição de um corpo físico. Diz respeito ao período que antecede à morte, período cuja duração varia de pessoa para pessoa e que é ocupado por um processo patológico grave irreversível. Constitui-se numa importante oportunidade de crescimento para o doente e seus familiares, pois, nos momentos de dor e de certeza da separação entre as pessoas, estas podem rever sua vida e seus valores, e então suplantar seus ressentimentos, exercitar o perdão e desenvolver a compreensão e o amor.

O doente terminal é o centro deste processo, é aquele que está gravemente doente e cuja esperança é a morte.

Abordar questões relacionadas à terminalidade e ao paciente terminal exige uma reflexão prévia sobre a morte, o morrer, e seus significados para o homem, uma vez que existe uma relação direta entre terminalidade e morte.

\footnotetext{
- Professores assistentes do Curso de Enfermagem da Universidade Federal de São Carlos.
} 
Várias são as concepções que se tem da morte. Não há definição única, depende do ponto de vista que se está discutindo. Aqui, interessa-nos a morte do ponto de vista fisiológico, que leva à ausência física do indivíduo no mundo e a dor decorrente da separação e perda.

Do ponto de vista clínico, a morte é entendida como a cessação total e permanente das funçōes vitais, que não se extinguem de uma só vez. Exceto na morte súbita, em geral ocorre uma falência progressiva dos mecanismos homeostáticos, variável no período de horas, dias ou semanas.(DUGAS, 1978 e FUERST et al., 1977).

Gradativamente, vão se instalando mudanças que nos dão clareza de que a morte é iminente, tais como:

- perda do tônus muscular: perda dos movimentos e sensibilidade; relaxamento dos esfincteres causando incontinência urinária e fecal, disfagia, acúmulo de secreções na orofaringe;

- desaparecimentos dos reflexos;

- alteração dos sentidos: visão embaçada, olhos secos, audição normal (é o último sentido a desaparecer);

- cessação progressiva do peristaltismo: decréscimo do apetite até inapetência;

- circulação lenta: pulso fino, rápido e irregular, queda da pressão arterial;

- respiração rápida, ruidosa e difícil até chegar ao tipo Cheyne-Stokes;

- boca seca;

- ligeira elevação da temperatura corporal;

- pela fria e pegajosa, sudorese;

- face cianótica com expressão de dor e angústia, sucedida de uma face pálida, com expressão de serenidade na fase final;

- extremidade cianoticas e com manchas;

- dilatação das pupilas (midríase);

- olhar fixo e boca aberta;

- desidratação, caquexia, infecção e escaras de decúbito, de correntes do desiquilíbrio do estado nutricional.

Frente às alterações acima mencionadas, a enfermagem e a família devem atuar no sentido de nutrir, promover a higiene e conforto do paciente para prevenir os desconfortos físicos adicionais.

Finalmente, a morte clínica é consumada quando são detectados os sinais de morte circulatória e morte cerebral. Os parâmetros para avaliar tais aspectos são muito variáveis e polêmicos em relação à sua duração. Diante disso, "a morte será a paralisação das funções respiratórias, cardíacas e cerebrais, por um tempo razoável que não deixem dúvidas quanto à permanência de vida" (FRANÇA, 1976).

De um modo geral são considerados os seguintes dados:

- ausência de respiração e pulsação ao longo de vários minutos, mesmo através de ausculta;

- midríase bilateral, completa;

- ausência total de reflexos; 
- insconsciência total e falta de resposta a estímulos externos;

- queda de pressão arterial;

- eletroencefalograma isoelétrico.

Do mesmo modo que entender a morte, é necessário entender o que é morrer, pois todos nós o vivenciamos sem termos consciência disto. Enquanto a morte finaliza, encerra um estágio, o morrer descreve a caminhada deste estágio, razão por que dizemos que estamos morrendo desde o momento da nossa concepçáo. $O$ morrer está pontuado por sucessivas mortes que antecedem a morte final e "tem o significado de transmutação ou desprendimento de energia vital de um ser humano ou de partes vivas no sentido diário, e no sentido do convencionalmente chamado final" (PADUAN, 1984). Essa transmutação significa "mudar-se de um estágio energético para outro" (WEILL, 1979).

A diferenciação entre morrer e morte é necessária porque o morrer está ocorrendo em nós a cada momento e, dependendo da forma como o vivemos teremos um medo mais ou menos intenso da morte. Conseqüentemente, lidar com a terminalidade tornar-se-á tarefa muito difícil, para nós.

O medo da morte sempre fez parte do comportamento humano desde as mais primitivas culturas. A forma de lidar com esse medo é que variou através dos tempos, facilitando ou dificultando as relações de escamoteamento frente a ela.

Existem dois planos de medo diante da morte. Um medo é o instintivo, natural, necessário, pois é aquele que ocorre quando nos vemos ameaçados ou em risco de perder a vida, como, por exemplo, quando vamos atravessar uma rua $\mathrm{e}$ vem um carro, paramos e o deixamos passar, se não o vemos e só o percebemos quando está próximo, nos assustamos, reagimos parando "estatelados". Outro é aquele que adquirimos através da nossa educação, de nossas relações e convivio social, que sofrem influência da cultura na qual estamos inseridos. Por exemplo, os orientais lidam muito melhor com o medo e a ansiedade diante da morte do que nós, os ocidentais. Esse outro medo năo faz sentido, ele não nos protege, ao contrário, traz muito mais complicações para o nosso viver e nossas emoções.

À medida que o homem não consegue perceber a morte como estágio de vida, um estágio de sua evolução (Kubler Ross, 1975), vamos encontrar, durante toda a história do seu comportamento diante da morte, as mais diversas formas de agir. Há desde uma aceitação da morte manifestada nos rituais coletivos, tribais, dos quais o proprio moribundo participa até chegar a hora da morte (KUBLER ROSS, 1975), até a total negação, manifestada através do desespero e do pânico individual, ou de formas mais bizarras de comportamento social como a construção de cemitérios longe das cidades como fizeram os povos das antigas civilizações (AIRES, 1977) com o temor de que os mortos viessem incomodá-los.

É importante salientar que não nascemos com essa segunda forma de medo. Ela vai se solidificando através dos tempos, haja visto como as crianças entendem a morte. A criança de até 3 anos de idade, por exemplo, percebe a morte como fato reversível. Do mesmo modo que sofre pela separação da mãe que a deixa para ir ao trabalho, ela sofre quando morre um ente querido. Porém espera que ele volte, assim como espera a mãe no retorno do trabalho.

Ainda a criança na idade pré-escolar associa a morte aos pensamentos mágicos e de mistério, consegue perceber a morte que acontece aos outros, mas 
não elabora a compreensão de que poderá morrer, sofre muito mais pela separação que precisa enfrentar do que pela morte.

$\mathrm{Na}$ idade escolar, com sua cognição já estruturada, a criança tem a compreensão da morte como uma separação irreversível e como a cessação da vida. Percebe-se no mundo como pessoa viva e já sabe que poderá morrer. É nessa fase que se solidificam os conceitos de que morte é algo ruim na vida das pessoas e aprende o seu significado através de experiências pessoais. Se a criança entrasse em contato com as situações de morte com naturalidade, do mesmo modo que entra em contato com a escola, com as separaçōes da vida diária, mais tarde, quando adulto, teria menos conflitos no que diz respeito à morte.

Já que falamos da percepção da criança em relação à morte, vale também ressaltar a postura do adolescente. Segundo BRUNNER; SUDDARTH (1980) "embora não possa compreender a morte como um fato que ocorre a pessoas que lhe são queridas, o adolescente compreende a morte como o adulto". Para o adolescente a morte é obstáculo para a realização de seus objetivos. O temor que experimenta vincula-se ao medo de não conseguir sua realização e, se ele estiver doente correndo o risco de morrer, sente-se rejeitado pelos companheiros, exprimindo com isso muita raiva, amargura e ressentimento.

Não muito diferente do adolescente, o adulto também experimenta muita dor e desespero ao defrontar-se com a questão da morte, sua ou do outro, devido a toda uma estrutura de negação que adquiriu ao longo dos anos de vida.

Este relacionamento com a morte, presente na cultura ocidental, está muito mais escamoteado, segundo ILLICH (1977), no presente século. Este escamoteamento e negação se prende a alguns aspectos importantes como o culto à juventude, à beleza, à velocidade, ao progresso e ao consumismo (D'ASSUMPÇÃO, 1981), que se relacionam intrinsicamente. À medida que se estimula o progresso através dos meios de comunicação e na própria conduta da ciência, e mais o avanço tecnológico como algo que assegura a vida, a morte não tem espaço para ser pensada, discutida e assumida, uma vez que ela interrompe a velocidade, $o$ progresso, e anula a beleza presente na matéria.

Para enfrentar a morte, muitas são as formas de reação do homem. KUBLER ROSS (1981) aponta 5 estágios pelos quais ele passa ao tomar conhecimento de que irá morrer por ser portador de uma doença grave e incurável. São eles: negação, raiva, barganha, depressão e aceitação.

Negação: quando a pessoa toma o primeiro contato com o seu diagnóstico e não acredita. Sofre um impacto intenso e diz: "Não! Não pode ser! Não são os meus resultados! Não é possível!" Acha que foi um erro de diagnóstico, procura outro profissional para atendê-lo. D'ASSUMPÇÃO (1987) diz que este estado é "mesmo importante pois funciona como uma pára-choques que alivia o impacto da notícia e dá tempo para melhor assimilarmos o que está acontecendo".

Raiva: após lutas em vão negando, a pessoa neste momento aceita a realidade, mas questiona: "Por que eu? Por que logo comigo?". A partir dessas perguntas não respondidas, emergem sentimentos de muita raiva. Ela agride os familiares, os profissionais que cuidam dela, e até mesmo Deus porque se sente abandonada por Ele. Esta situação fica ainda mais complicada à medida que os familiares também vivenciam estes estágios e contra-agridem a pessoa doente.

Barganha ou negociação: depois da negação e da raiva, a pessoa toma um novo modo de agir na tentativa de assegurar sua vida, procurando encontrar saf- 
das através da oração e promessas, e então negocia com Deus e passa a se envolver com atividades caridosas.

Depressão: à medida que seus esforços empreendidos não resultam na sua melhora, a pessoa "recolhe-se". Desanimada na busca de solução definitiva não encontrada, vai tomando consciência de que não há retorno, e passa a se preparar para o final. Fica algum tempo muito calada, reflexiva. Questiona sua vida, procura rever sua conduta, mostra interesse em resolver os problemas ainda não resolvidos. "Seus interesses ficam limitados a sua propria vida ou ao seu fim" (D’ASSUMPÇÄO, 1987). Este período é vivido com muita autenticidade, razão pela qual surpreende aos que the cercam.

Aceitação: é a culminância das fases anteriores. A pessoa está muito tranqüila, sobretudo se resolver suas questões conflituosas, principalmente as afetivas. Não se percebe nela a presença de sentimentos (nem felicidade, nem infelicidade). Percebe-se, sim, muita paz, como se ela e o cosmo fossem um so, amorfos. A pessoa deixa de se preocupar com o que acontece no mundo ou à sua volta. Responde a estímulos mas não se afeta com eles. A característica primordial desta fase é o pleno desapego, como se fosse gradativamente se desvinculando, se separando dos seus afetos e do seu proprio corpo.

O conhecimento dessas etapas é muito importante, porque todos nós as percorremos todas as vezes que nos vemos ameaçados de perder algo significativo em nossas vidas, não apenas na morte. Além de conhecer, também precisamos saber lidar com essas questóes para estarmos mais preparados. A melhor forma de conseguirmos esta preparação é:

- empreender um trabalho exaustivo de tomada de consciência das nossas dificuldades frente à morte e lidar com elas procurando entendê-las, compartilhá-las com outras pessoas, efetuar leituras e até mesmo procurar psicoterapia;

- diminuir nosso apego aos objetos e às pessoas;

- estabelecer relacionamentos mais positivos, lidando com as nossas emoções nāo sadias;

- ter e manter nosso nível de esperança elevado, diante da vida e da terminalidade nossa e do outro;

- fazer reflexões e encontrar o sentido da vida para nós, e o sentido da nossa relação com o cosmo;

- viver cada dia como se fosse o último;

- buscar sempre a qualidade de vida, através do atendimento comedido às nossas necessidades básicas;

- valorizar e reconhecer a existência do outro e da nossa própria, expressando este reconhecimento emitindo mais carícias positivas (SHINYASHIKI, 1989);

- falar da morte e do morrer com mais freqüência (com sentido positivo e não trágico);

- visitar pessoas em fase terminal desde a infância, como um recurso educativo para a compreensão da morte. 
Situações no tocante à terminalidade e que requerem atitudes de envolvimento profissional

\section{A - Situações de decisão}

\section{Contar ou não contar o diagnóstico de uma doença grave ao doente?}

Agir nestas circuntâncias, depende do doente, de como ele está, se quer ou não saber do diagnóstico. D'ASSUMPÇÃO (1987) considera que a descoberta do diagnóstico $e$ inicialmente intuitiva, feita "por vias interiores". Para o autor, o doente sabe da doença e sua gravidade, mesmo que não saiba exatamente o que tem. Por isso questiona, mas não tem respostas reais da família nem da equipe de saúde. A verdade deve ser sempre dita, porém é preciso saber se o doente quer ouvi-la. Ele oferece dicas como: "Será que tenho doença ruim? Eu vou morrer? O que eu tenho é grave?". Perguntas como estas abrem espaços para se sondar o interesse do paciente em saber o que tem.

Existem situações constrangedoras para a família e até mesmo para o terapeuta quando o doente ainda nao conhece o seu diagnóstico e precisa fazer tratamentos como quimioterapia, radioterapia, etc. Às vezes a propria situação obriga a abrir-se o jogo com ele, pois ele descobrirá de qualquer modo. $O$ paciente, principalmente o alfabetizado, não é "tolo", lerá o nome da clínica especializada, ouvirá falar de doenças na clínica ou ambulatório. É preferível que seja informado a descobrir que está sendo enganado.

Outras vezes o doente pode não se interessar, devido à própria negação. Sua atitude deve ser aceita e seu momento respeitado, não se deixando de lado os tratamentos a serem realizados.

Em geral, cabe ao médico contar ao paciente a sua doença, de maneira que não tire a sua esperança de viver, relatando a ele as possibilidades de tratamento.

Fazer ou não fazer tratamentos quimio ou radioterápicos, quando a doença está avançada?

Esta dúvida é muito comum principalmente entre os familiares que conhecem ou já vivenciaram experiências com esses tratamentos. Realmente o tratamento é sofrido e mutilante para algumas pessoas, mais para umas do que para outras. Essa decisão não e da família e sim do doente. E imprescindível que haja um bom relacionamento do médico e demais profissionais de saúde com o doente para que haja confiança mútua e consequente segurança por parte do doente a fim de que possa fazer a sua opção com tranquilidade.

\section{Fazer tratamento em casa ou no hospital?}

Quando o doente se encontra em estado avançado da doença, já cansado de tratamento e hospitalizações, é comum recusar-se a voltar para novas internações. A família fica desesperada porque não sabe o que fazer para cuidar dele, 
atenuar suas dores em casa e preferiria levá-lo para o hospital, sempre na esperança de oferecer o melhor cuidado possível. Nesse momento há o impasse, pois, além da dificuldade de prestar os cuidados, também tem medo de que ele morra, e não consegue avaliar o quanto se sentirá culpada por não ter lhe oferecido assistência médica nos momentos finais da vida. Nesse sentido é sempre correto respeitar a decisão do doente e ter em mente que a atitude mais humanizada é aquela que lhe permite estar junto dos seus familiares, no seu ambiente doméstico e que, ao morrer, esteja amparado no apoio daqueles que lhe são afetos. Essa atitude é benéfica para os que morrem e para os que ficam, a medida que presenciam a morte e têm a oportunidade de prestar os cuidados com o corpo do ente querido que faleceu, podendo vivenciar a separação e a elaboração do significado da propria morte. Também é importante que os serviços de saúde estejam mais organizados e possam oferecer atendimento qualificado ao paciente e seus familiares, bem como que os profissionais sejam melhor preparados e humanizados nesse sentido.

\section{Reanimação e prolongamento da vida, o que fazer?}

A reanimação do paciente depende muito do seu estado, e se está somente com as funções vegetativas, sem capacidade de qualquer tipo de interação, é questionável a reanimação.

Da mesma forma, a aplicação de infusões e tranfusões ou uso de aparelhos quando o cérebro já está comprometido, significa protelar a vida sem benefício algum, e aumentar o sofrimento.

Devemos refletir-se, ao insistirmos em reanimar e prolongar a vida, não estamos querendo "satisfazer" nossas próprias necessidades que ocorrem pela nossa incapacidade de aceitar a morte.

\section{Como tratar as questões de bens materiais pertencentes ao doente em fase terminal?}

Esta questão é bastante séria para os familiares do paciente que vivenciam a terminalidade e não ultrapassam as fases da negação e da raiva. Durante a vida, todos nós nos preocupamos muito pouco em deixar nossas vidas em ordem, nossas documentações e bens devidamentes atualizados e corretos. Quando a doença ocorre, muitas vezes as pessoas estão desprevenidas economicamente, bem como nas questóes de ordenança de seus pertences e documentos. Se o doente não atinge a fase de depressão (interiorização) em que compreende sua terminalidade e espontaneamente procura resolver as questōes dos relacionamentos afetivos, emocionais e materiais, há necessidade da família abordá-lo nesse sentido ou até mesmo tomar atitudes mais urgentes. Nesse momento, instala-se a dificuldade para a família colocar a questão para ele, bem como a de ele aceitar as colocaçóes feitas por seus familiares devido a seu apego. Muitas vezes ocorrem conflitos, ficando diff́cil a situação para ambos, família e paciente.

A família precisa da ajuda de alguém. Nesse caso sempre é indicada a ajuda de pessoas mais íntimas, de melhor relacionamento do paciente, que, com diálogo delicado, poderá despertar o paciente para a compreensão deste problema sem feri-lo. 
A melhor forma, no entanto, de solucionar questões dessa natureza é prevenir através da conscientização das pessoas para esses aspectos salientando-se que a eternidade física não nos é um atributo, e que todos nós devemos nos organizar nesse sentido.

Do mesmo modo, é aconselhável que tenhamos conta bancária conjunta, mantenhamos algum familiar informado de nossas transações financeiras, pois nenhum de nós está insento do risco de sofrer um acidente ou até mesmo de adoecer e ficar impossibilitado de realizar nossos compromissos de sustento de vida.

\section{Visitas aos pacientes terminais, devem ou não ser liberadas?}

A questão da visita é séria em situações de terminalidade, pois essa fase constitui-se num período em que, dependendo do estágio vivenciado pelas pessoas, há grandes mudanças no comportamento entre elas. Há oportunidades para perdão, para a autenticidade e confronto, podendo ocorrer verdadeiros "encontros", devido à chance de revisão de vida e realizações efetivas plenas, que ocorrem principalmente entre os doentes e seus familiares. Esse estágio para alguns grupos familiares tem um carater extremamente terapêtico, semelhante aos "grupos de encontros" divulgados por ROGERS (1978). Para alguns, no entanto, esse período pode ser de extrema solidão, havendo sentimentos fortes de abandono e rejeição (como no caso do Aidético).

Ambas as razões justificam a liberação de visitas aos doentes, em sua casa ou no hospital. Porém estas devem ser feitas de modo organizado para que não o cansem e agravem seu quadro físico e emocional, bem como o da família. Os profissionais de saúde e mesmo a família devem orientar as visitas alertando quanto às conseqüências de sua presença, isto $e, o$ aumento do cansaço do doente, a possibilidade de contaminação, bem como os riscos a saúde dele e a dificuldade nos cuidados a lhe serem dados.

A UTI não é um local apropriado para pacientes em fase teminal. A restrição de visitas, geralmente de 5 minutos por pessoa, pode ser contraditória para a situação de familiares com alguém em estado de morte iminente. Esses pacientes deveriam ficar em outro local. Mas enquanto esta ainda é uma realidade, salientamos a necessidade de humanização nas UTIs conforme enfatizam, SOUZA, et al (1985).

Nesse sentido alertamos quanto à necessidade de compreensão para com os pacientes e seus familiares, neste setor, tornando as rotinas de visitas mais flexíveis, entendendo que a aparente piora emocional do paciente visitado pode significar que ele esteja manifestando suas emoções às pessoas amigas, até então contidas (Simão, 1976, apud, Souza, et al, 1985).

\section{B - Formas especiais de comunicaçăo:}

\section{Morte súbita, como agir?}

É importante, no caso de morte súbita por acidente ou doença aguda, que o próprio médico participe à família. Isso contribui para acalmar a revolta. A 
morte não deve ser comunicada por telefone ou no corredor, ou na emergência. De preferência, deve ocorrer numa sala mais tranqüila onde a família possa receber assistência psicológica e extravasar as suas emoçōes. Deixar que vejam o corpo, se desejarem, é uma medida importante para ajudar a encarar a realidade da morte.

O que nós podemos fazer é ficar à disposição da família que, devido ao choque, é incapaz muitas vezes de encaminhar as providéncias que são necessárias apos o falecimento.

\section{Como comunicar a morte d̀ criança?}

Diante da necessidade de informar à criança sobre a morte dos pais, devese contatar um parente próximo de boas relações para contar. Dizer que seus pais não as podem visitar, mas que o parente no caso está a caminho. Se insistir em saber dos pais, contar a verdade. Deixá-la expressar a emoção que vier à tona. Não falar muito no esforço de consolá-la.

\section{Como lidar com a mãe que perde um filho ao nascer?}

Pode-se ajudar a mãe que perde o filho ao nascer, ou logo após o nascimento, ficando à disposição, oferecendo carinho, empatia, enfim, presença.

Em situações de aborto também é necessário que a mãe seja informada corretamente sobre o destino do feto. Quando possível, dependendo das condições do feto e do seu interesse, é importante mostrar-lhe o concepto morto, mantendo-se ao lado dela, oferecendo lhe apoio e encorajamento.

\section{C - Informações complementares:}

Quando um corpo vai para a necrópsia:

A necropsia é realizada quando ocorre morte violenta (acidente, homicidio, suicídio, etc) que exige esclarecimento da causa. Trata-se de um exame realizado com objetivos de detectar a causa mortis.

\section{O feto morto é considerado cadáver?}

Quando pesar 500 gramas ou mais, é considerado natimorto e deve ser providenciado atestado, certidão de óbito e os funerais, como qualquer outro 6 bito. Quando o feto não é enquadrado nessas características, é encaminhado para incineração.

A mola, partes do corpo e esqueleto também não são considerados cadáveres, e são encaminhados para incineração. 
Medidas a serem tomadas quando a morte ocorre e o papel profissional na orientação e ajuda d familia.

Tecidos os comentários anteriores, cabe-nos ainda salientar as medidas a serem tomadas ao ocorrer a morte, ou seja:

a - comunicar d familia se o doente faleceu no hospital;

b - atestar o b́bito: o atestado de óbito é emitido pelo médico que acompanha o doente, se este falece no domicílio. Se a morte ocorrer no hospital, o médico plantonista é quem assina o atestado. Se a morte ocorrer em casa, a famflia procura um médico de sua confiança para confirmar o obito e assinar $o$ atestado, quando a morte for súbita.

c - solicitar a presença de uma funerária a qual cuidará do sepultamento: quando) o obito ocorreu no hospital, o próprio serviço social se encarrega dessa tarefa, pois alguns hospitais detêm em mãos listas de funerárias em plantão. E importante estar inteirado de qual funerária funciona com preços mais acessiveis ou esquemas de pagamentos mais facilitados, pois a família, nesse momento de dor, nem sempre tem condições de decidir essas questões e precisa da ajuda de alguém.

d - velório: para a família que não está preparada, o velório tem um importante sentido, é uma oportunidade para ela encarar a realidade da morte do seu ente querido principalmente se a morte foi súbita ou inesperada.

e - cuidados com o corpo após o bbito: se a morte ocorreu no domićlio, os cuidados poderão se efetuados por pessoas da família preferencialmente, podendo ser os mesmos descritos para o obito no hospital. Alguns familiares preferem não faze-lo; tal tarefa poderá ser efetuada pela própria funerária. Quando o obito ocorrer no hospital, a funerária ou a equipe de enfermagem presta os cuidados ao corpo. Esta última poderá consultar os familiares se alguém tem interesse em ajudar. Os cuidados a serem efetuados podem variar conforme a situação, mas podem ser da seguinte forma, segundo MAMEDE (1984):

\section{MATERIAL:}

- par de luvas,

- frasco com éter ou benzina,

- aparelho de barbear, se necessário,

- pinça longa,

- algodão hidrófilo

- esparadrapo,

- atadura de crepe,

- balde com solução desinfetante,

- biombo,

- recipiente para lixo,

- material para banho, se necessário,

- hamper,

- etiqueta para identificaçăo, cordone

- dois lençóis

- maca. 
TÉCNICA:

- encaminhar o aviso de óbito ao setor competente;

- lavar as mãos;

- reunir o material;

- desligar todos os equipamentos;

- abaixar a cabeceira da cama;

- cercar com biombos, se for o caso;

- retirar sondas, cânulas, drenos e colocá-los no balde com desinfetante;

- dar o banho, se for o caso;

- barbear, se for necessário;

- limpar e colocar as próteses se houverem;

- fazer curativos, se for o caso;

- fechar as pálpebras com tiras de esparadrapo, se necessário, e retirá-los após mais ou menos uma hora;

- sustentar a mandíbula com atadura de crepe, amarrando-a no alto na cabeça (retirar apos uma hora);

- tamponar os orifícios naturais do corpo (nariz, ouvido, boca, ânus e vagina) com algodão seco e o auxílio de pinça longa de tal maneira que não apareça o algodão;

- vestir a roupa no paciente se o corpo foi liberado;

- unir as mãos sobre a cintura e fixá-las com uma atadura de crepe, se necessário;

- unir os pés e também fixá-los com atadura de crepe;

- amarrar a etiqueta com cordoné nos tornozelos, se o corpo for para necropsia;

- forrar a maca com lençol em diagonal;

- cobrir o corpo e maca com outro lençol, em sentido longitudinal;

- remover a roupa da cama e colocá-la no hamper;

- reunir, empacotar os pertences do paciente e entregá-los à família;

- encaminhar o corpo ao local determinado para aguardar;

- lavar as mãos;

- fazer as anotaçōes pertinentes;

- deixar a unidade limpa e em ordem;

Todos os cuidados devem ser feitos com respeito, postura ética, competência e segurança.

f - assistência à família no momento da morte: levar os familiares para um lugar privativo onde possam permanecer juntos e exporem suas emoçōes através do choro. Oferecer apoio, permanecer ao lado, segurar-lhe as mãos, abraçálos, se permitirem. Oferecer água, chás, etc. Quando houver algum familiar que, devido à tensão, tem alterações de saúde, acomodá-lo em cadeira confortável, controlar os seus sinais vitais e solicitar a presença do médico plantonista se necessário. Verificar se há interesse da família em providenciar assistência espiritual a seus membros ou ao ente querido. Quando alguém promoteu que estaria presente no momento da morte e foi impossível, é comum o aparecimento de sentimentos de culpa. É preciso ajudar essa pessoa. Também é comum ocorrer revolta contra a equipe que cuidou do paciente. 
Deixar que extravassem toda sua raiva, que chorem sem reprimir, ouvir a família permanecendo ao lado dela, ou retirar-se quando a mesma pedir. Dizer que tipo de assistência foi dada, e quando não o melhor é escutar os desabafos.

$\mathrm{g}$ - orientar no momento propício, o registro em cartório: de posse do atestado de obito, a família deverá procurar um cartório de registro civil para efeturar o registro de óbito, ocasião em que receberá uma certidão de obito.

$\mathrm{h}$ - orientar, também oportunamente, o encaminhamento de documentos para solicitar: o pagamento de pensão. PIS e FGTS, junto ao INSS (Instituto Nacional de Seguridade Social): para isto é necessário a apresentação da certidão de óbito, carteira profissional da pessoa falecida e certidão de casamento.

\section{A dor diante da morte e luto:}

Temos na dor uma grande inimiga, pelas razões culturais e educativas que incialmente já apontamos. No entanto, não é bem assim. Toda a dor e sofrimento se constituem num processo de crescimento pessoal, apesar do desconforto que provocam. Quando ocorre a morte, aqueles que ficam sentem um grande vazio em suas vidas qualquer que seja a idade. Algumas pessoas chegam a perder o próprio sentido da vida. Por essa razão tendem ao isolamento, ao choro contido, não se alimentam, apresentam insonia, etc. Outros ainda abandonam os afazeres, os estudos e buscam o álcool na tentativa de atenuar o desconforto pela perda.

Nessas situações é preciso que as pessoas amigas, profissionais de saúde e familiares estejam atentos e ofereçam ajuda através de atitudes como: ouvi-las, deixá-las chorar à vontade, convidá-las e levá-las a lugares não muito movimentados. Ajudá-las a fazer gradativamente os afazeres domésticos e trabalhos fora do lar, fazer-lhes companhia nos horários mais difíceis, geralmente ao anoitecer.

As vezes temos o falso conceito de que as pessoas enlutadas ao se afastarem dos objetos, pertences e situações relacionadas à pessoa que morreu, sentirse-åo melhor. É preciso muito cuidado para que se mantenha o respeito ao ritmo de elaboração da perda vivenciada pelas pessoas. Conviver com situações dessa natureza ajuda-as na assimilação mais rápida da ausência do ente querido.

O cuidado em evitar decisões precipitadas de mudanças, de distribuição de pertences, é imprescindível para quem sofre perda de entes queridos.

\section{A emoção do profissional diante da morte}

Emocionar-se é uma grande capacidade do homem que não deve ser inibida pelo profissionalismo.

Quando desempenhamos nosso papel profissional com envolvimento e interesse genuínos pelo doente, é natural que sua morte nos provoque dor. Cada um de nós, no entanto, expressa de maneira diferente essa dor e, portanto, pode chorar e compartilhar a dor com os familiares dos doentes dos quais cuidou e aprendeu a gostar. Isso nos torna profissionais mais humanizados. 


\section{Conclusåo}

Ao concluirmos este artigo, queremos enfatizar a necssidade de maior humanização do homem frente à sua vida e a dos outros. Urge uma grande transformação das pessoas no mundo de hoje para que se possam reduzir as atitudes de violência contra a humanidade e com a propria morte, que passa a ser usada indevidamente nas mãos daqueles a quem pouco importa a vida. Também é urgente a necessidade de humanização das instituições de saúde, principalmente naqueles setores em que se lida com a terminalidade. Os pacientes de oncologia, de AIDS e outros, estão a todo momento a reclamar pelos maltratos, pela indiferença às dores que vivenciam nos atendimentos hospitalares e ambulatoriais. Concorrendo com suas dores físicas, suas debilidades, encontram filas de espera para atendimento, profissionais negligenciando atendimento à medida que suas prescriçס̋es terapêuticas são questionadas ou recusadas pelos pacientes.

Em meio a essa desumanização, estão os familiares que se vêm desesperados à procura de melhores atendimentos, pagando o que não têm em consultorios particulares para garantir atendimento mais humanizado para seu doente. Mesmo assim, essa nem sempre é a melhor saida porque ouvem sempre a mesma coisa: "o câncer é assim mesmo, não temos muito o que fazer, ela tem que aguentar a dor...". Com a institucionalização na saúde, a desqualificação do doente aumenta dia a dia. $O$ baixo nível de atendimento de enfermagem nos hospitais continua. A negligência nos atendimentos médicos hospitalares aumenta dia a dia por conta das especialidades. Nesse momento temos saudade da velha história da enfermagem e da medicina, em que o médico da família era o que de tudo entendia um pouco e errava menos, e a enfermagem no domićlio se fazia presente para o verdadeiro apoio e trabalho preventivo. Saudosismo ou não, a verdade é que ansiamos muito por uma humanização urgente das instituiçóes e dos profissionais de saúde para que os doentes terminais e seus familiares possam viver suas experiências com mais respeito e dignidade.

OLIVEIRA, M. A. P. de ; OGASAWARA, M. Contribution to deal with death situation. Rev. Esc. Enf. USP., v. 26, n. 3, p. - , dec, 1992.

The present paper was produced in order to help students, to deal with the death situation. It focus on conceps and conflicts related to terminal stage, death and post-death period, which demands attitudes of involvement of the professional in this situation, and other complementary informations about the whole issue.

UNITERMS: Terminal illness. Death. Nursing care.

\section{REFERENCIAS BIBLIOGRÁFICAS}

1. AIRES, P. Historia da morte no acidente: da idade média aos nossos dias. Rio de Janeiro, Francisco Alves, 1977

2. BRUNNER, L. S.; SUDDARTH, D.S. Modema prática de enfermagem. Rio de"Janeiro, Interamericana, 1980.

3. D'ASSUNPÇĀO, E. A Aspectos culturais, psicológicos e religiosos da morte. $O$ Recado, v. 28, p. 12-25, 1981. 
4. D'ASSUNPÇĀO, E. A Os que partem e os que ficam: orientaçăo sobre sofrimento e a morte. Belo Horizonte, O Lutador, 1987.

5. DUGAS, B. W. Enfermagem prática. 3. ed. Rio de Janeiro, Interamericana, 1978, cap. 32, p. 491-6, 1978: Paciente em estágio terminal.

6. FRANÇA, G. V. Legislação da morte. Rev. Paul. Enf., v. 24, no9, p. 425-9, 1976.

7. FUERST, E. et al. Fundamentos de enfermagem. 5. ed. Rio de Janeiro. Interamericana. 1977, cap. 31, p. 464-77: Cuidados do paciente quando a morte é iminente.

8. ILliCH, I. A expropiação da saúde. Rio de Janeiro, Nova Fronteira, 1977.

9. KUBLER ROSS, E. Morte estágio final da evolução. Rio de Janeiro, Record, 1975.

10. Penguntas e respostas sobre a morte e o morrer. Săo Paulo, Martins Fontes, 1979.

11. - Sobre a morte e o morrer. Såo Paulo, Martins Fontes, 1981.

12. MAMEDE, M. et al. Técnicas de enfermagem. São Paulo, Sarvier, 1984, cap. 1, p. 8-10: Técnicas usadas em enfermagem médico-cirúrgica.

13. PADUAN, M. A. A educação dos alunos de graduação de enfermagem em relação d morte e ao momer. Ribeirăo Preto, 1984. 124p. Dissertaçāo (Mestrado) - Escola de Enfermagem de Ribeirão Preto, Universidade de São Paulo.

14. ROGERS, C. Grupos de encontros. São Paulo. Interamericana, 1978.

15. SHINYASHIKI, R. Cartcia essencial. São Paulo, Ed. Gente, 1989.

16. SOUZA, M. de et al. Humanização da abordagem nas unidades de terapia intensiva. Rev. Paul. Enf., v.5, $n^{9} 2$, p. 77-9, 1985.

17. WEIL, P. As fronteiras da evolução e da morte: os limites de transformação da energia do homem. Petropolis, Vozes, 1979. 